\title{
RELATIONSHIP BETWEEN SNACKING HABITS AND CARIES EXPERIENCE A COMPARATIVE STUDY BETWEEN EGYPTIAN AND KUWAITI CHILDREN
}

\author{
Yomna S.A.Mohamed*, Hadil A. Sabry ** and Manar Mohammed
}

\begin{abstract}
Background: Dental caries is a chronic, multifactorial disease, with limited background data available for the Egyptian and Kuwaiti populations. Aim of this study was to compare the prevalence of dental caries among Egyptian and Kuwaiti children in correlation with snacking habits and oral hygiene measure.
\end{abstract}

Subjects and Methods: A total number of 360 Egyptian and kuwaiti children, each group comprised of 180 children (aged between 3-12 years)were examined over the period from $3^{\text {rd }}$ August 2019 till $6^{\text {th }}$ of October 2019.Demographic data, snacking habits and frequency of tooth brushing for children were recorded in a questionnaire. Dental status was analyzed using decayed, missing and filled index (dmf) for deciduous dentition and (DMF) index for permanent dentition. For mixed dentition (def ) index d(decayed),e (decayed tooth indicated for extraction) and f (filled tooth).

Results: Kuwaiti children who had unhealthy ,mixed snacks (healthy/Unhealthy), twice daily, at different time of the day (BL/LD) and brushing their teeth twice daily had a significantly higher value of DMF than the Egyptian children. Also, The Kuwaiti children had a significantly higher dmf score than the Egyptian children regarding healthy snacks, mixed snacks, twice daily, at different time of the day (BL/LD) and brushing their teeth twice daily. Finally, the Kuwaiti children showed higher statistically significant difference score of def regarding Unhealthy and twice daily snacks than the Egyptian children .

Conclusion: Our findings suggest that Kuwaiti children have higher caries prevalence than Egyptian children.

KEYWORDS: Children, Snaking habits, Brushing teeth, Dental caries Index (DMF/def/dmf).

Abbreviation :BL=Between breakfast and lunch / LD=Between Lunch and dinner / Healthy snacks=Fruits and Vegetables/Unhealthy snacks :snacks including candy, soft drinks, chocolates, jelly, ice cream, potato chips , cookies ./Mixed:(Healthy/Unhealthy snacks).

* Lecturer, Department of Pediatric and community Dentistry, Faculty of Oral and Dental Medicine, October 6 University, Giza,Egypt.

** Assistant Professor of Biomaterials, Faculty of Dentistry, October 6 University 


\section{INTRODUCTION}

Dental caries is a major public health issue which is considered as one of the most widespread chronic disease affecting 2.43 billion people worldwide ${ }^{(1)}$. In 2003, WHO and FDI established global goals for oral health in 2020 to guide planners and policy makers to improve the oral health status in their populations $^{(2)}$.

Dental caries is a multifactorial disease which is initiated when simple carbohydrates are fermented by the bacteria which collect in dental plaque biofilm inside the mouth ${ }^{(3)}$. It can affect any age and it is highly related and affected by the patient's dietary habits, sugar intake, salivary flow, salivary fluoride level and preventive behaviors. These factors together with time encourage the microbial residence in the accumulated dental plaque to initiate dental caries $^{(4)}$.

Dental caries has shown an overall decline worldwide in developed countries ${ }^{(5)}$. Such changes are detected in parallel to improved socio-economic conditions, changing life-styles, self-care practices, use of fluorides and effective use of preventive oral health care services ${ }^{(6)}$

The incidence of dental caries varies greatly among different populations, with its higher incidence in developing countries including the middle east compared to its incidence in developed countries $^{(7)}$. Despite the high prevalence of dental caries in the Egyptian population, only a few epidemiological studies of dental caries among Egyptians have been published. The most recently published epidemiological study on the oral health status in Egypt was held by WHO in collaboration with the Egyptian Ministry of Health in 2014(8). Kuwait is one of the few countries in the Gulf region where national oral health surveys have been conducted, There is a national system of health care, all children have access to oral health care located in clinics, polyclinics, specialist centers and simultaneously dental care is also expanding in the private sector $^{(9)}$.
Many factors such as occupational status, family income, and level of education of parents have been commonly associated with dental caries however ,their relative influence on dental caries compared to individual factors is unclear ${ }^{(10)}$. Furthermore, modification of socioeconomic factors requires macro level changes which is time consuming. In contrary, individual factors such as child oral health behaviors and dietary habits which play a role in cariogenesis could be targeted for modification by directing resources to school children. Previous studies revealed the importance of adopting good oral health behaviors such as regular brushing of teeth in decreasing the disease burden and attaining optimal oral health ${ }^{(11)}$.

Diet plays an important role in the nutritional status and hence forward the development of children $^{(12)}$. Sugars are the most important dietary etiological cause of dental caries. The frequent consumption of carbohydrate containing snacks between meals is known to increase greatly the amount of dental caries. ${ }^{(13)}$ However, the relative significance of aforementioned oral behavioral factors on cariogenesis compared to other host factors could vary considerably in different populations due to cultural and behavioral practices. There is relatively little information about the amount of sugar consumed and patterns of consumption in developing countries ${ }^{(14)}$.

Children form the backbone of future generation and many serious diseases later in life have their initial origins in childhood ${ }^{(15)}$. Unhealthy lifestyle factors like skipping meals and food choice leading to a poorer nutrient intake are common among this vulnerable young age group ${ }^{(16)}$. Children are giving preferences for sweetened foods and soft drinks ${ }^{(17)}$ that are rich in carbohydrate and thus are at risk for caries development ${ }^{(18)}$. The pattern of dental caries in children depends on the timing of tooth eruption as well as harmful dietary habit. ${ }^{(19)}$

Therefore, this study was conducted to evaluate the prevalence of dental caries among Egyptian and 
Kuwaiti children in relation to gender, snacking habits and frequency of tooth brushing.

\section{SUBJECTS AND METHODS}

\section{Study population}

This cross-sectional study was conducted between both countries Egypt and Kuwait. A total of 360 children participated in the study, each group comprised 180 children between the age range of 3-12 years from preschool and school children seeking dental care in private clinics in Egypt and Kuwait. The study protocol was approved by ethical review committee and written informed consent was signed by the parents/guardians of the children. The criteria for selection of the study subjects were that the children should be permanent residents in Egypt with both Egyptian parents for the Egyptian sample while for the Kuwaiti sample that the children should be permanent residents in Kuwaiti with both parents are of Kuwaiti origins.

\section{Sample size calculation:}

A power analysis was designed to have adequate power to apply a 2-sided statistical test of the research hypothesis that there is no difference between active cement compared to dual cured resin cement. According to the results of Khattab, Nancy $\mathrm{AF}^{(20)}$. effect size (w) was calculated and found to be $(0.198)$. By adopting an alpha $(\alpha)$ and $(\beta)$ levels of $0.05(5 \%)$ i.e. power $=95 \%$; the predicted sample size (n) was found to be a total of (331) cases. Sample size calculation was performed using PASS $15^{(21)}$.

\section{Questionnaire format and content:}

The questionnaires were completed by caregiver and the content includes the following information: (1) demographic information including age and sex of the children as well as the education level and occupation of their parents or primary caregiver (2) the diet habits of the children, such snacking habits, type of snacks, the number of times of snacks per day, timing of snacks, whether unhealthy snacks including candy, soft drinks, chocolates, jelly, ice cream, cookies and potato chips or healthy snacks including fruits and vegetables. (3) Frequency of brushing per day.

\section{Screening for dental caries}

Oral examination for both groups was carried out according to WHO criteria on a dental chair, in artificial light, by using sterilized plain mouth mirror and a dental probe. ${ }^{[22]}$ All present teeth were taken into consideration during the clinical examination $^{(23)}$. Caries severity was measured for permanent teeth by DMFT index, which records the number of D (decayed tooth), M (missing tooth) and F (filled tooth). For primary teeth the dmft index was used; d (decayed teeth, $\mathrm{m}$ (missed teeth) and f (filled tooth). For mixed dentition deft index was used; d (decayed tooth indicated for filling), e (decayed tooth indicated for extraction) and $\mathrm{f}$ (filled tooth) ${ }^{(24)}$.

\section{Statistical analysis:}

Categorical data were presented as frequencies and percentages and were analyzed using chi square test. Ordinal data were represented by mean and standard deviation (SD) values and were analyzed using Mann-Whitney U test. Spearman rank order correlation coefficient was used to study the correlation between caries scores and different risk factors. The significance level was set at $p \leq 0.05$ within all tests. Statistical analysis was performed with IBM SPSS Statistics Version 26 for Windows. IBM Corporation, NY, USA. ( ${ }^{\circledR S P S S}$, Inc., an IBM Company.

\section{RESULTS}

\section{Descriptive statistics:}

Descriptive statistics were presented in figure 1

Majority of the children in the Egyptian group 97 (53.9\%) and the Kuwaiti group 95 (52.8\%) 
groups were females and there was no significant difference in gender distribution in both groups $(p=0.916)$. There was a significant difference in the distribution of children in different age groups $(\mathrm{p}<0.001)$, with most of the children in the Egyptian group $92(51.1 \%)$ being 6-12 years old while in the Kuwaiti group, a higher percentage of children 120
(66.7\%) were 3-6 years old. Figure 1

\section{Intergroup comparisons of DMF score (Table 1)}

Kuwaiti children who had unhealthy snacks or mixed snacks had a significantly higher value of DMF score (2.06 \pm 0.64$)$ and (1.57 \pm 0.94$)$ than the Egyptian children $(1.13 \pm 1.63)$ and $(0.70 \pm 1.43)(\mathrm{p}=0.001$ and

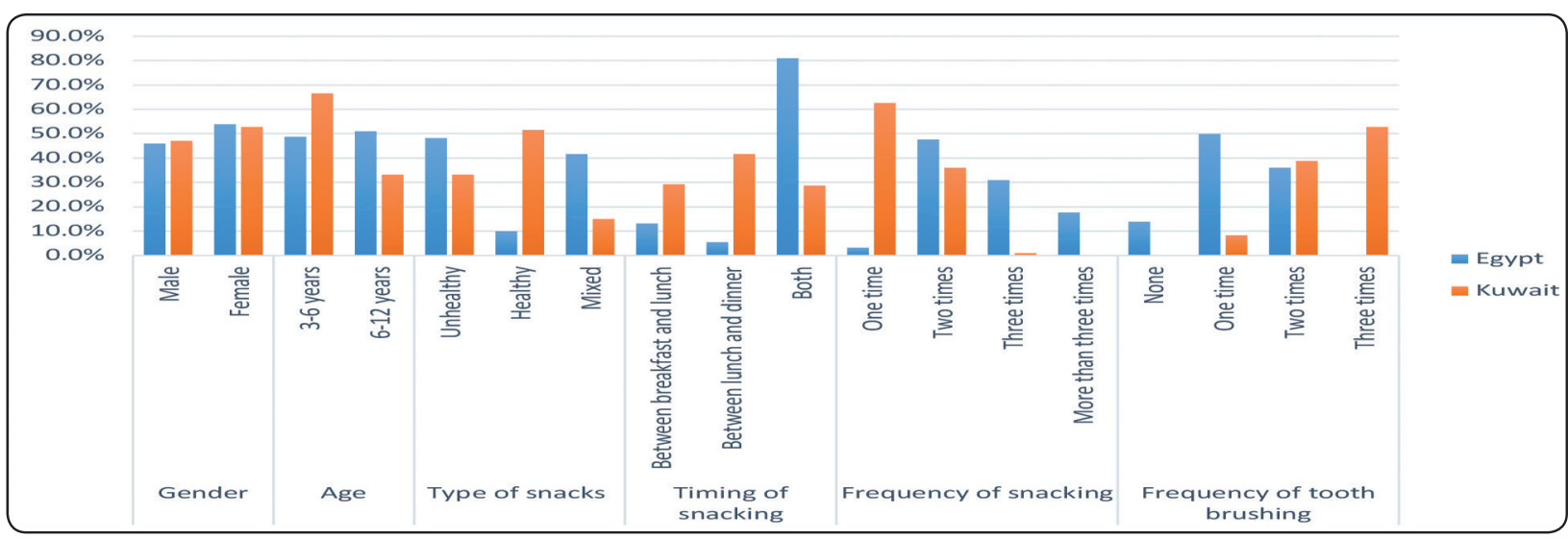

Fig. (1): Bar chart showing percentage of different demographic and risk factors in both groups.

TABLE (1) Intergroup comparison of DMF score

\begin{tabular}{|c|c|c|c|c|}
\hline \multirow{2}{*}{\multicolumn{2}{|c|}{ Parameters }} & \multicolumn{2}{|c|}{$\mathrm{DMF}(\mathrm{Mean} \pm \mathrm{SD})$} & \multirow{3}{*}{$\begin{array}{c}\text { p-value } \\
0.431 \mathrm{~ns}\end{array}$} \\
\hline & & \multirow{2}{*}{$\begin{array}{c}\text { Egyptian } \\
0.63 \pm 1.16\end{array}$} & \multirow{2}{*}{$\begin{array}{c}\text { Kuwaiti } \\
1.38 \pm 1.01\end{array}$} & \\
\hline Cord & Male & & & \\
\hline 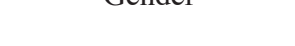 & Female & $1.08 \pm 1.73$ & $1.06 \pm 1.00$ & $0.349 \mathrm{~ns}$ \\
\hline \multirow{3}{*}{ Type of snacks } & Unhealthy & $1.13 \pm 1.63$ & $2.06 \pm 0.64$ & $0.001 *$ \\
\hline & Healthy & $0.63 \pm 1.41$ & $0.50 \pm 0.69$ & $0.591 \mathrm{~ns}$ \\
\hline & Mixed & $0.70 \pm 1.43$ & $1.57 \pm 0.94$ & $<0.001 *$ \\
\hline \multirow{3}{*}{ Timing of snacking } & Between breakfast and lunch & $0.27 \pm 0.70$ & $0.67 \pm 0.89$ & $0.135 \mathrm{~ns}$ \\
\hline & Between lunch and dinner & $1.00 \pm 1.00$ & $0.95 \pm 0.97$ & $0.879 \mathrm{~ns}$ \\
\hline & Between breakfast and lunch/lunch and dinner & $0.99 \pm 1.62$ & $1.62 \pm 0.94$ & $<0.001 *$ \\
\hline \multirow{4}{*}{ Frequency of snacking } & One time & $1.00 \pm 1.41$ & $0.84 \pm 0.93$ & $0.839 \mathrm{~ns}$ \\
\hline & Two times & $0.43 \pm 0.94$ & $1.62 \pm 0.94$ & $<0.001 *$ \\
\hline & Three times & $1.15 \pm 1.56$ & - & - \\
\hline & More than three times & $1.75 \pm 2.24$ & - & - \\
\hline \multirow{4}{*}{$\begin{array}{c}\text { Frequency of tooth } \\
\text { brushing }\end{array}$} & None & $2.27 \pm 1.91$ & - & - \\
\hline & One time & $0.62 \pm 1.35$ & $1.00 \pm 0.0$ & $0.235 \mathrm{~ns}$ \\
\hline & Two times & $0.67 \pm 1.30$ & $1.17 \pm 1.01$ & $0.004 *$ \\
\hline & Three times & - & $1.29 \pm 1.04$ & - \\
\hline
\end{tabular}

*; significant $(p \leq 0.05) n s ;$ non-significant $(p>0.05)$ 
$<0.001)$ respectively. In addition, Kuwaiti children who had their snacks at different times (BL/LD) of the day and twice daily had a significantly higher value of DMF score $(1.62 \pm 0.94)$ than the Egyptian children $(0.99 \pm 1.62)$ and $(0.43 \pm 0.94) \quad(\mathrm{p}<0.001)$ respectively. Finally, Kuwaiti children who brushed their teeth twice daily had a significantly higher value of DMF score $(1.17 \pm 1.01)$ than the Egyptian children $(0.67 \pm 1.30) \quad(\mathrm{p}=0.004)$. For all other parameters, there was no significant difference between both groups $(\mathrm{p}>0.05)$.

\section{Intergroup comparisons of def score (Figure2)}

Kuwaiti children who had an unhealthy snacks (5.33 \pm 3.39$)$ had a significantly higher def score than the Egyptian children $(3.33 \pm 1.37)(\mathrm{p}=0.048)$. In addition, Kuwaiti children who had their snacks twice daily had a significantly higher value of def score $(4.04 \pm 1.20)$ than the Egyptian children
$(2.98 \pm 2.85)(\mathrm{p}=0.006)$. For all other parameters, there was no significant difference between both groups $(\mathrm{p}>0.05)$.

\section{Intergroup comparisons of dmf score (Table 2)}

Kuwaiti children who had healthy snacks or mixed snacks had a significantly higher dmf score $(3.54 \pm 1.45)$ and $(4.00 \pm 1.47)$ than the Egyptian children $(2.40 \pm 4.01)$ and $(1.87 \pm 2.09)(\mathrm{p}=0.004$ and $0.003)$ respectively. In addition, Kuwaiti children who had their snacks twice daily had a significantly higher value of $\mathrm{dmf}$ score $(4.06 \pm 1.62)$ than the Egyptian children $(1.42 \pm 1.59)(\mathrm{p}<0.001)$. Finally, Kuwaiti children who brushed their teeth twice daily had a significantly higher value of $\mathrm{dmf}$ score (3.69 \pm 1.41$)$ than the Egyptian children $(2.40 \pm 2.84)$ $(\mathrm{p}=0.017)$. For all other parameters, there was no significant difference between both groups $(p>0.05)$

TABLE (2) Intergroup comparison of dmf score

\begin{tabular}{|c|c|c|c|c|}
\hline \multirow{2}{*}{\multicolumn{2}{|c|}{ Parameters }} & \multicolumn{2}{|c|}{$\operatorname{dmf}($ Mean \pm SD $)$} & \multirow{3}{*}{$\begin{array}{c}\mathrm{p} \text {-value } \\
0.431 \mathrm{~ns}\end{array}$} \\
\hline & & \multirow{2}{*}{$\begin{array}{c}\text { Egyptian } \\
3.89 \pm 3.90\end{array}$} & \multirow{2}{*}{$\begin{array}{c}\text { Kuwaiti } \\
3.89 \pm 1.53\end{array}$} & \\
\hline Gondor & Male & & & \\
\hline (6) & Female & $3.92 \pm 3.63$ & $3.77 \pm 1.55$ & $0.349 \mathrm{~ns}$ \\
\hline \multirow{3}{*}{ Type of snacks } & Unhealthy & $5.46 \pm 3.77$ & $4.21 \pm 1.63$ & $0.148 \mathrm{~ns}$ \\
\hline & Healthy & $2.40 \pm 4.01$ & $3.54 \pm 1.45$ & $0.004 *$ \\
\hline & Mixed & $1.87 \pm 2.09$ & $4.00 \pm 1.47$ & $0.003 *$ \\
\hline \multirow{3}{*}{ Timing of snacking } & Between breakfast and lunch & $3.78 \pm 3.63$ & $3.73 \pm 1.53$ & $0.691 \mathrm{~ns}$ \\
\hline & Between lunch and dinner & $2.17 \pm 1.94$ & $3.68 \pm 1.49$ & $0.051 \mathrm{~ns}$ \\
\hline & Both & $4.10 \pm 3.88$ & $4.35 \pm 1.61$ & $0.218 \mathrm{~ns}$ \\
\hline \multirow{4}{*}{ Frequency of snacking } & One time & $2.50 \pm 2.08$ & $3.77 \pm 1.49$ & $0.189 \mathrm{~ns}$ \\
\hline & Two times & $1.42 \pm 1.59$ & $4.06 \pm 1.62$ & $<0.001 *$ \\
\hline & Three times & $4.46 \pm 2.38$ & $2.00 \pm 0.00$ & $0.109 \mathrm{~ns}$ \\
\hline & More than three times & $9.50 \pm 4.36$ & ---------- & --------- \\
\hline \multirow{4}{*}{ Frequency of tooth brushing } & None & $9.20 \pm 5.27$ & ---------- & ---------- \\
\hline & One time & $3.40 \pm 2.59$ & $4.36 \pm 1.28$ & $0.095 \mathrm{~ns}$ \\
\hline & Two times & $2.40 \pm 2.84$ & $3.69 \pm 1.41$ & $0.017 *$ \\
\hline & Three times & ---------- & $3.79 \pm 1.64$ & ---------- \\
\hline
\end{tabular}

*; significant $(p \leq 0.05) n s ;$ non-significant $(p>0.05)$ 


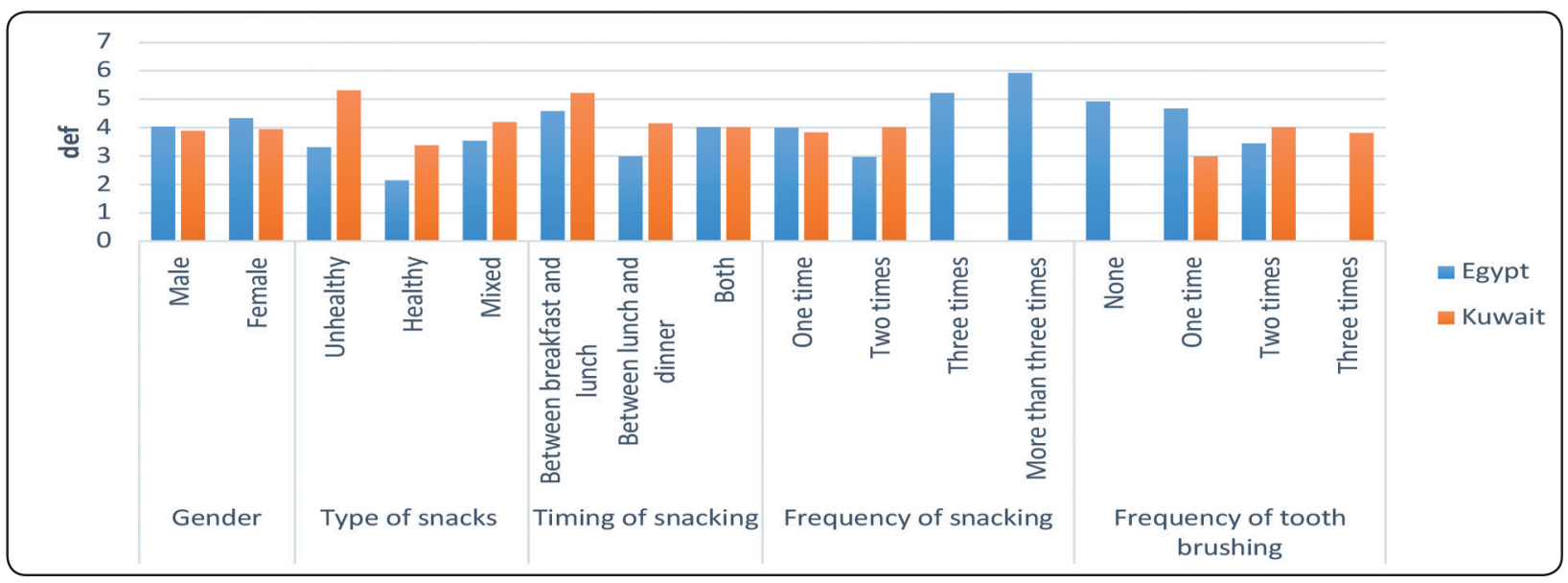

Fig. (2): Bar chart showing average def score in both groups

\section{DISCUSSION}

In many developing countries, the prevalence of dental caries has been increasing including the middle East. The relationship between the development of carious lesions and dietetic factors has been investigated since the 1940s and it has been suggested that the association between sugar intake and the development of carious lesions is currently different from that recognized in the past decades, since dental health has improved significantly in the developed countries, with no parallel decrease in the consumption of sugar and cariogenic foods ${ }^{(25)}$.

This study comprised of 360 children, each group included 180 children, aged 3-12 years . This study was an attempt to present a comprehensive overview and information about the caries and its relation to different characteristics of dietary habits and oral hygiene measure in an attempt to explore the effect of culture context on caries prevalence and caries experience. Searching the dental literature ,no previous studies compared the caries prevalence between Egyptian and Kuwaiti children. Therefore, the aim of this study was to compare between these two cultural different countries where these two groups represent a diverse set traditional believes regarding the dietary pattern of the children.
In this study, there was a significant difference in the distribution of children in different age groups $(p<0.001)$, most of children in the Egyptian group $92(51.1 \%)$ being 6-12 years old while in the Kuwaiti group, a higher percentage of children 120 (66.7\%) were 3-6 years old. Also ,the majority of children in the Egyptian group (53.9\%) and the Kuwaiti group $(52.8 \%)$ groups were females, however, there was no significant difference in gender distribution in both groups $(\mathrm{p}=0.916)$.

The statistical results of this study showed that Kuwaiti children had a significantly higher value of DMF ,dmf and def than the Egyptian children as regards unhealthy snacks ,healthy snacks , mixed ( healthy/unhealthy)snacks, twice daily and snacking at different time of the day (BL/LD). The higher caries prevalence in Kuwaiti children may be due to the socioeconomic development, cultural habits change since the 1970s rise in oil prices and may be related to the diet rich in refined carbohydrates. Also the frequent consumption of sugars, especially sweets, fruit drinks and desserts could be higher in Kuwait associated with possible higher socioeconomic status and cultural differences than Egypt .These findings were comparable with the study results by Al-Khateeb et al., 1991 (26) accomplished on children in private schools in 
Kuwait. Also our findings in harmony with earlier study results by Glass et al.,1982 ${ }^{(27)}$ and Behbehani and Shah, 2002(28). However, Murtomaa et al., $1995^{(29)}$ disagree with our findings in a study carried out in a private school in Kuwait where children would be considered of higher socioeconomic and educational levels and demonstrated low caries index and higher percentages of caries-free children.

Also in our study, Kuwaiti children who brushed their teeth twice daily had significantly higher value of DMF and dmf scores than Egyptian children and this could be due to higher frequency of intake of unhealthy snacks between meals which may lead to maintain low $\mathrm{pH}$ of saliva for prolonged time and hence increase dental caries.Our findings agreed with $\mathrm{Yu}$ et al., 2008(30) who found children that brush their teeth once or twice a day have a higher number of decayed teeth as well as a worse index of dental caries than those who brush three or more times a day.

\section{Limitation Of The Study}

- A larger and more detailed longitudinal study could help in understanding the relationship between diet and dental caries including private and public clinics.

- The dental caries in this research were recognized only by clinical examination, no radiographs which may over- or under-estimate the actual extent of the problem.

- The current study did not discriminate between different kinds of sweets consumed by children.

\section{RECOMMENDATIONS}

The following recommendations are suggested to improve overall oral health status among children with snacking habits:
1- Care givers should advise the children on the unpleasant effects of frequent consumption of sugary snacks on their health and its damaging effect on the teeth. Teachers in school can also contribute in oral health and healthy eating habits education of the children, which can help in behavior changes among these children and would take forward into their adult life.

2- The Effect of increasing carbohydrate exposure, including consumption of sodas and juice drinks on the rate of dental caries should be further considered and awareness should be assumed to prevent dental caries.

\section{REFERENCES}

1. Vos T, Flaxman AD, Naghavi M, Lozano R, Michaud C, Ezzati M, et al.(2010) Years lived with disability (YLDs) for 1160 sequelae of 289 diseases and injuries 1990-2010: a systematic analysis for the Global Burden of Disease Study. Lancet. 2012;380(9859):2163-96.

2. Hobdell M, Petersen PE, Clarkson J, Johnson N. Global goals for oral health 2020. Int Dent J. 2003; 53(5):285-8.;World Health Organization. WHO Oral health country/area profile project. Available from: http:// www.mah.se/capp/. accessed 17.07.14.

3. Carlos JP. Epidemiology of oral diseases in children. In: Forrester DJ, Wagner ML, Fleming J, eds. Pediatric dental medicine. Philadelphia: Lea and Febinger, 1981:1-6.

4. Selwitz RH, Ismail AI, Pitts NB: Dental caries.Lancet. 2007;369(9555):51-59.

5. Holm, A.K. (1990): Caries in the preschool child: internationaltrends. Journal of Dentistry 18, 291-295.

6. Bratthall, D., Hansel-Petersson, G. and Sundberg, H. (1996): Reasons for the caries decline: what do the experts believe?European Journal of Oral Sciences 104, 416-422.

7. Leake J, Jozzy S, Uswak G: Severe dental caries, impacts and determinants among children 2-6 years of age in Inuvik Region, Northwest Territories, Canada.J Can Dent Assoc. 2008;74(6):519.

8. http://www.emro.who.int/egy/egypt-events/results-ofepidemiological-study-on-oral-health-status-released. html.2014 
9. Al-Mutawa S, Shyama M, Al-Duwairi Y and Soparkar P Dental caries experience of Kuwaiti schoolchildren (2006) Community Dental Health 23, 31-36.

10. Narang R, Mittal L, Jha K, Anamika R. Caries experience and its relationship with parent's education, occupation and socio economic status of the among 3-6 years old preschool children of Sri Ganganagar City, India. Open journal of dentistry and Oral Medicine. 2013;1(1):1-4.]

11. [Amin TT, Al-Abad BM. Oral hygiene practices, dental knowledge, dietary habits and their relation to caries among male primary school children in Al Hassa, Saudi Arabia.(2008) Int J Dent Hyg;6(4):361-70

12. Moynihan P. The interrelationship between diet and oral health. Proc Nutr Soc. 2005;64:571-80.

13. Rugg-Gunn AJ. The relationship between diet and dental caries in 2 and 4 year old children in the Emirate of Abu Dhabi. Saudi Dental Journal. Sep-Dec. 2000;12(3).

14. Ismail A I, Tanzer J M, Dingle J L. Current trends of sugar consumption in developing societies. Community Dent Oral Epidemiol.December 1997;25(6):438-443.

15. Petersen PE, Kjoller M, Christensen LB, et al. : Changing dentate status of adults, use of dental health services, and achievement of national dental health goals in Denmark by the year 2000.J Public Health Dent. 2004;64(3):127-135.

16. Sjöberg A, Hallberg L, Höglund D, Hulthén L. Meal pattern, food choice, nutrient intake and lifestyle factors in the Göteborg Adolescence study. Eur J Clin Nutr. 2003;57:1569-78.

17. Drewnowski A, Mennella JA, Johnson SL, Bellisle F. Sweetness and food preference. J Nutr. 2012;142:1142S-8.

18. Shenkin JD, Heller KE, Warren JJ, Marshall TA. Soft drink consumption and caries risk in children and adolescents. Gen Dent. 2003;51:30-6.

19. Que G, Hou W.(2009)[Epidemiological investigation on deciduous dental caries among children aged 2 approxi- mately 4 years of Kaifu district in Changsha city].Zhong Nan Da Xue Xue Bao Yi Xue Ban;34(1):76-80.

20. Khattab, Nancy Af. "Relationship Between Dietary Habits and Caries Experience Acomparative Study Between Egyptian And Nubian Children."

21. PASS 15 Power Analysis and Sample Size Software (2017). NCSS, LLC. Kaysville, Utah, USA, ncss.com/software/pass

22. World Health Organization: Oral Health Surveys: Basic Methods. World Health Organization, Geneva, Switzerland. 1997.

23. Jokić NI, Bakarčić D, Janković S, et al. : Dental caries experience in croatian school children in Primorsko-Goranska county.Cent Eur J Public Health. 2013;21(1):39-42.

24. World Health Organization: Oral health surveys: Basic methods. 5th ed., Geneva, Switzerland, World Health Organization.2013.

25. Doichinova L, Bakardjiev P, Peneva M: Assessment of food habits in children aged 6-12 years and the risk of caries.BiotechnolBiotechnol Equip. 2015;29(1):200-204.

26. Al-Khateeb T.L., Al-Marsafi, A.I. and O'Mullane, D.M. (1991): Caries experience and treatment need amongst children inan Arabian community. Community Dentistry and OralEpidemiology 19, 277-280

27. Glass, R.L. (1982): Kuwait national dental healthsurvey, part 1. The oral health of school children in 5-16 years of age in Kuwait 1982. Kuwait: Ministry of Health.)

28. Behbehani, J.M. and Shah, N.M. (2002): Oral health in Kuwait before the Gulf war. Medical Principles and Practice11(suppl 1), 36-43.).

29. Murtomaa, H., Al Za'abi, F., Morris, R.E. and Metsaniitty, M.(1995): Caries experience in a selected group of children in Kuwait. ActaOdontologicaScandinavica53, 389-391

30. Yu HJ, Huang ST, Chen HS. Association of dietary and dental hygiene habits with the prevalence of dental caries of 6-12 year-old schoolchildren in eastern Taiwan. Taiwan J Oral Med Sci 2008;24:37e48 